Article

\title{
Comparison of Branch Water Relations in Two Riparian Species: Populus euphratica and Tamarix ramosissima
}

\author{
Duan $\mathrm{Li}^{1,2}$, Jianhua $\mathrm{Si}^{1,2, *}$, Xiaoyou Zhang ${ }^{1,2}$, Yayu Gao ${ }^{1,2}$, Huan Luo ${ }^{1,2}$, Jie Qin ${ }^{1,2}$ \\ and Guanlong Gao ${ }^{3}$ \\ 1 Key Laboratory of Eco-Hydrology of Inland River Basin, Northwest Institute of Eco-Environment and \\ Resources, Chinese Academy of Sciences, Lanzhou 730000, China; liduan@lzb.ac.cn (D.L.); \\ zhangxy@lzb.ac.cn (X.Z.); gaoyayu18@mails.ucas.ac.cn (Y.G.); huanluo@lzb.ac.cn (H.L.); \\ qinjie18@mails.ucas.ac.cn (J.Q.) \\ 2 University of Chinese Academy of Sciences, Beijing 100049, China \\ 3 Department of environment and resources, Shanxi University, Taiyuan 030006, China; \\ gaoguanlong@sxu.edu.cn \\ * Correspondence: jianhuas@lzb.ac.cn
}

Received: 14 August 2019; Accepted: 29 September 2019; Published: 2 October 2019

\begin{abstract}
Water relations in plants maintain healthy tree branches and drought conditions during plant growth may affect water relations, but the mechanisms are poorly known. In our study, we determined the stomatal conductance, hydraulic conductance, water potential and ion concentration of xylem sap to increase the understanding of changes in water relations in branches of Populus euphratica (P. euphratica) and Tamarix ramosissima (T. ramosissima), which are the dominant plant species in the lower reaches of the Heihe River Basin in China. The results showed that both species responded to vapor pressure deficit (VPD) during the growing season by adjusting stomatal conductance to achieve homeostasis in leaf water potentials. The leaf-specific hydraulic conductance (LSC) of the branch was determined using water status in the branch, and the LSC of the leaf was determined using water status in the leaf. Because of homeostasis in leaf water potentials, hydraulic conductance in leaves remained stable. As a result, branch dieback, which might be induced by deficits in water supply, could rarely be seen in T. ramosissima owing to the homeostasis in branch and leaf water status. The ion sensitivity of xylem hydraulic conductance in P. euphratica induced an increase in hydraulic conductance caused by the deficits in the water supply which might lead to branch dieback. The evaluation of water relations provides a further understanding of the internal mechanisms of drought acclimation for riparian plants.
\end{abstract}

Keywords: Populus euphratica; Tamarix ramosissima; water relations; stomatal conductance; hydraulic characteristics; water status; ion sensitivity

\section{Introduction}

Drought constitutes one of the most critical challenges facing species and ecosystems. Drought resistance is related to water relations in plants and it helps determine the growth, development, and competitiveness of plant species [1]. Stomatal conductance, hydraulic characteristics and water status determine water relations in branches. Stomata act as a major pathway limiting water loss from the leaf to the atmosphere; stomatal control allows plants to carry on carbon assimilation, respiration, and transpiration in fluctuating environmental conditions [2]. Stomatal conductance could be controlled by water relations in plants from the soil to evaporation in leaves. Plants may respond through the adjustment of stomatal conductance when xylem tension is caused by water deficits in 
the soil-to-leaf pathway [3]. The plant must maintain the movement of water and rapid stomatal responses to environmental changes, which are a vital feature of maintenance [4]. The changes in stomatal conductance could reflect the changes in water relations during the growing season.

Past studies have shown that hydraulic properties are related to plant drought resistance [5]. An essential feature of the survival and healthy growth of a drought-tolerant plant is the ability to adapt to the oasis environment characterized by wet-dry fluctuations, and the ability to sustain effective hydraulic conductance under drought stress [1,6]. Water transfer efficiency, expressed as leaf-specific hydraulic conductance (i.e., scaling the hydraulic conductance of specific organ to the leaf area), is an essential index of water supply capacity which defines water supply to the evaporating surfaces, and reflects the ability of plants to supply water to the leaves $[7,8]$. Significant seasonal changes in ion concentration in xylem sap have been shown in some species $[9,10]$; hydraulic conductance in the xylem is sensitive to cation concentration (e.g., $\mathrm{K}^{+}, \mathrm{Ca}^{+2}$ ) in xylem sap, because pit membranes in vessels are altered by the swelling and shrinking of pectins, which could be regulated by specific inorganic ions [9]. Thus, xylem hydraulic conductance increases in response to increases and decreases in response to a decrease in xylem sap ion concentration [11,12]. The changes in hydraulic conductance could also reflect the changes in water relations during the growing season.

River basins in the arid inland region of China exhibit downstream oases formed by riparian forests. Lower reaches of the Heihe River Basin located in the Alxa Plateau, has a temperate desert climate. The oasis environment fluctuates from dry to wet as a result of the distance from the river and seasonally artificial discharge of water from the upper reaches of the Heihe River. There is a vast natural forest belt, approximately $200 \mathrm{~km}$ long and 1 to $15 \mathrm{~km}$ wide, which plays important roles in protecting biodiversity and preserving the ecosystem functions of inland river basins $[13,14]$. Populus euphratica (P. euphratica) and Tamarix ramosissima (T. ramosissima) are the dominant species in these riparian forests. The P. euphratica forest in the research area, covering an area of approximately $1500 \mathrm{~km}^{2}$, is one of the only three existing P. euphratica forests in the world (Figure 1). However, branches of P. euphratica are dying in many areas, suggesting ecological degradation. Tree mortality is likely with prolonged branch dieback. As for T. ramosissima, this phenomenon is rarely noticed in this area. The reasons for branch mortality and the difference between the behavior of the two species are unclear but may be related to changes in water relationships in these plants.

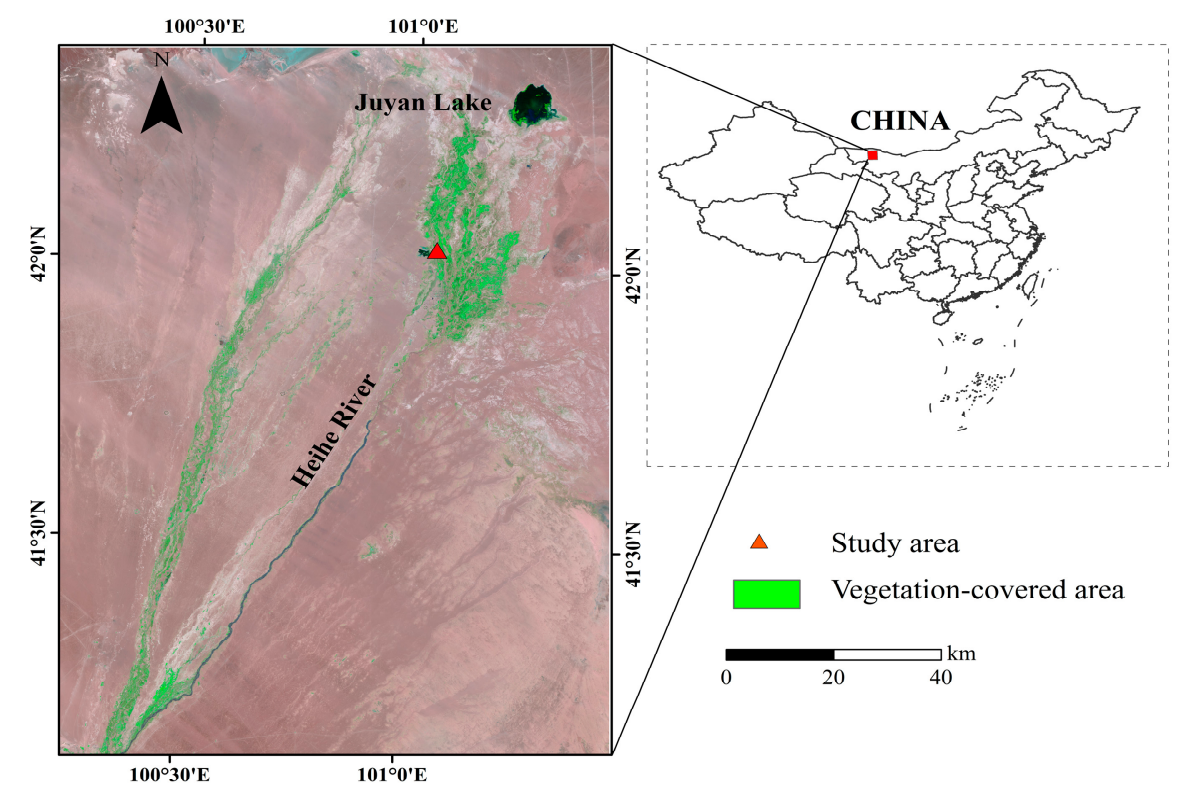

Figure 1. Remote sensing images of downstream oases in the Heihe River Basin in the arid inland region of China. 
Previous studies compared the relationships between groundwater and hydraulic conductance in P. euphratica and T. ramosissima or the relationships between xylem anatomy and hydraulic conductance, separately [15-18]. There is little research on the reason for the seasonal change in hydraulic conductance and water status with seasonal change months. There is also no evidence for changes in the ion concentration of xylem sap and the ion sensitivity of hydraulic characteristics in the two species. Only a few previous studies demonstrated the difference in P. euphratica and T. ramosissima in changes in plant water relations during the growing season, which has great importance related to differences between the two species in branch dieback since they are keystone species in their habitats.

To address the growing season water relations in the branches of P. euphratica and T. ramosissima, we studied the seasonal trends in stomatal conductance, plant water status, hydraulic properties, and ion concentration of xylem sap in nursery-grown stock planted in a field. Our aim was to provide physiological information for the mechanistic interpretation of seasonal trends in plant water relations. We measured these parameters in live branches and simulated plant dehydration. We aimed to answer the following questions: (1) do the two species differ in stomatal conductance and, if so, why? (2) do the two species differ in hydraulic characteristics and, if so, why?, and (3) do the two species differ in ion sensitivity and why?

\section{Materials and Methods}

\subsection{Study Sites}

Our study was conducted in the Alxa Desert Eco-hydrology Experimental Research Station of the Chinese Academy of Sciences, located in the lower reaches of the Heihe River Basin, in northwestern China $\left(42^{\circ} 01^{\prime} \mathrm{N}, 100^{\circ} 21^{\prime} \mathrm{E}\right.$, altitude $\left.883.54 \mathrm{~m}\right)$. The research area is representative of the typical hyper-arid region of China and exhibits severe salinization and desertification. Local groundwater originates mainly from discharge from the middle and upper reaches of the river [16]. The annual average temperature is $8.2^{\circ} \mathrm{C}$ and the annual precipitation totals $38 \mathrm{~mm}$ - of which, $75 \%$ occurs between June and August. In this area, annual evaporation exceeds $3390 \mathrm{~mm}$ and surpasses precipitation by a factor of 90. The dominant riparian species, P. euphratica, and T. ramosissima, were researched in our study. The soil in the area is derived from fluvial sediment, with gray-brown desert sediments [19]. The study was conducted during the growing season of the species from June to September 2018. The highest and lowest temperature during the study period were 38.65 and $5.31^{\circ} \mathrm{C}$, respectively. The average temperature, relative humidity, and vapor pressure deficit were $24.54{ }^{\circ} \mathrm{C}, 38.53 \%$, and $2.19 \mathrm{kPa}$, respectively. The mean groundwater depth was approximately $2.25 \mathrm{~m}$.

\subsection{Plant Materials}

P. euphratica and T. ramosissima saplings were used to examine the characteristics of hydraulics. Saplings of the two species were grown in a nursery for approximately one and a half years before they were transplanted into the field. Saplings at an average height of $30 \mathrm{~cm}$ were transplanted to the research station area in mid-April 2017. Both saplings of the two species were grown in the same place under the natural environment. We chose 60 saplings of each species that were healthy, straight, non-stressed, and growing well. The average height and diameter at breast height (DBH) of these saplings were $74 \mathrm{~cm}$ and $0.7 \mathrm{~cm}$, respectively. One or two branches $(2-3 \mathrm{~mm}$ in diameter, approximately $80 \mathrm{~mm}$ in length) were obtained from each main stem of three trees per species at a time for measurements.

\subsection{Measurement of Hydraulic Conductance}

We determined hydraulic conductance $\left(k, \mathrm{~kg} \mathrm{~s}^{-1} \mathrm{MPa}^{-1}\right)$ with the water perfusion method and a high-pressure flow meter (HPFM-GEN3, Dynamax Inc., Houston, TX, USA) [20]. The HPFM consists of an apparatus forcing distilled water into the base of the root system or the shoot and measuring flow simultaneously with forcing; hydraulic conductance was then obtained from a relationship between 
applied pressure and flow rate. Flow measurements in branches were made with the HPFM operating in the "steady mode" with a stable pressure of $350 \mathrm{kPa}$ until the rate of water flow entering the shoot stabilized. Each sequence of flow measurements lasted approximately $10 \mathrm{~min}$. Data were corrected for a reference temperature of $25^{\circ} \mathrm{C}$ to compensate for changes in water viscosity due to differences in measurement temperatures [20]. Monthly measurements of $k$ were determined at 06:00, 10:00, 14:00, 18:00, and 24:00 $\mathrm{h}$ from June to September on typical sunny days for three trees per species at a time.

One or two branches obtained from each tree were enclosed in dark plastic bags containing wet towels and immediately transported to the laboratory. The bases of branches were re-cut underwater to prevent air from entering into the xylem. Leaf blades were removed to obtain new hydraulic conductance values. Leaf hydraulic conductance is a measure of the ease with which liquid water travels through the leaf $[10,21]$. The hydraulic conductance of the leaf $\left(k_{l}\right)$ was calculated based on Ohm's law hydraulic pressure analog, as follows [22]:

$$
k_{l}=\left(k_{b}{ }^{-1}-k_{x}^{-1}\right)^{-1}
$$

where $k_{b}$ was the hydraulic conductance of a fully leafed branch and $k_{x}$ was the hydraulic conductance of a bare branch with petioles for $P$. euphratica and a bare branch for T. ramosissima.

The measured hydraulic conductance was adjusted to the total leaf area to obtain leaf-specific hydraulic conductance ( $L S C, \mathrm{~kg} \mathrm{~s}^{-1} \mathrm{MPa}^{-1} \mathrm{~m}^{-2}$ ), $k_{l b}$ was the leaf-specific hydraulic conductance of the branch and $k_{l l}$ was the leaf-specific hydraulic conductance of the leaf. In addition, the calculation method of the total leaf area was described below.

\subsection{Total Leaf Area}

Total leaf area for both species was estimated from total leaf biomass and specific leaf weight (SLW, leaf area/biomass) without a petiole. Ten leaves were obtained from each of the 60 saplings for this purpose. These leaves were pasted on grid paper to draw the outline. We counted the number of squares in which leaf-covered $>50 \%$ of the grid area. Then, the leaf area was calculated from the number of squares multiplied by the area of a single grid $(1 \mathrm{~cm}$ by $1 \mathrm{~cm}$ with 25 squares of equal area). Leaves were then dried at $80^{\circ} \mathrm{C}$ and weighed on an electronic balance to obtain biomass and SLW (leaf area/biomass) of each tree. Finally, the total leaf area was determined by adding dry weights of all leaves, assuming the same SLW for each individual tree [23].

\subsection{Gas Exchange}

Leaf stomatal conductance $\left(g_{s}, \mathrm{~mol} \mathrm{H}_{2} \mathrm{O} \mathrm{m}^{-2} \mathrm{~S}^{-1}\right)$ and transpiration $\left(E, \mathrm{mmol} \mathrm{H}_{2} \mathrm{O} \mathrm{m}^{-2} \mathrm{~s}^{-1}\right)$ were measured directly in attached leaves under ambient conditions using a portable LI-6400 photosynthesis system (LI-COR, Lincoln, NE, USA). Gas exchange in P. euphratica was determined using the Standard Chamber (i.e., ambient photosynthetically active radiation was measured by clear-top chamber systems clear-top chamber systems) and that in T. ramosissima was determined using the 6400-05 Conifer Chamber. We used three fully extended green leaves on each shoot for P. euphratica and three clusters of needles on the treetop for T. ramosissima.

\subsection{Measurement of Water Status}

A nitrogen-driven pressure chamber (PMS Instruments, Corvallis, OR, USA) was used to measure water potential $\left(\Psi_{x}, \mathrm{MPa}\right)$ of small shoots (2-3 $\mathrm{mm}$ in diameter, $80 \mathrm{~mm}$ in length). The shoots were excised from the middle of the canopy between the hours 13:00-14:00 using a sharp blade. The $\Psi_{x}$ was determined in the presence of foliage; leaves were sealed with aluminum foil and encased with a plastic bag to prevent transpiration [24]. The $\Psi_{x}$ was recorded when the first drop of xylem sap flow was observed emerging from the cut end of the shoot. Measurements were repeated using six samples per species taken from different trees. 
The leaf water potential $\left(\Psi_{l}\right)$ was calculated from the soil-to-leaf pathway based on Ohm's law analogy as follows [6]:

$$
\Psi_{l}=\Psi_{x}-E / k_{l l}
$$

where $k_{l l}$ was the leaf-specific hydraulic conductance of leaves which was calculated for the soil-to-leaf pathway to characterize the changes in transport capacity, and $E$ was the transpiration rate of leaves.

\subsection{The Electrical Conductivity of Xylem Sap}

To check for seasonal variability in the concentration of cations in xylem sap, sap samples were collected from the stems at noon. The distal part with leaves was cut to obtain twig samples with the same length, and the end removing bark was girdled to prevent any contamination of xylem sap with phloem exudate. Twigs were connected to the hydraulic apparatus at their proximal end and perfused at a pressure of $9 \mathrm{kPa}$ with distilled water. Then xylem sap of twigs was collected from the other end of the twigs within the first five minutes [25]. Sap collection for measurements was repeated using six twigs per species taken from different trees. Then, sap samples were stored in a refrigerator at $4{ }^{\circ} \mathrm{C}$. Each xylem sap sample was transferred to a $5 \mathrm{~mL}$ tube and brought to the volume by ultrapure water for measurements. Finally, electrical conductivity was determined with a digital display conductivity meter for comparison of relative magnitudes.

\subsection{Dehydration Treatment}

To simulate an extremely dry environment, leafy branches obtained from 10 trees were collected at noon for dehydration treatment. Those branches were enclosed in dark plastic bags with wet towels and then transported to the laboratory. Branches were placed horizontally on a test bench and exposed to the air for $0,0.5,1,2,4$, and $6 \mathrm{~h}$ to develop a series of decreasing water potentials. We used $3-4$ branches for each treatment duration. Both hydraulic conductance and water potential were simultaneously determined.

Immediately following the dehydration treatment, we measured transpiration (E, mmol $\mathrm{H}_{2} \mathrm{O} \mathrm{m}^{-2} \mathrm{~s}^{-1}$ ) using an LI-6400 portable photosynthesis system (LI-COR, Lincoln, NE, USA). We used three fully-elongated leaves on each shoot for the measurements for P. euphratica, and three clusters of needles grown at the top of each branch with the entire leaf chamber covered by the leaves for T. ramosissima. LI-COR settings were $1200 \mu \mathrm{mol} \mathrm{m}^{-2} \mathrm{~s}^{-1}$ for light intensity (with $6400-02 \mathrm{~B}$ red-blue LED Light Source) and $400 \mu \mathrm{mol} \mathrm{mol}^{-1}$ for $\mathrm{CO}_{2}$ concentration (using $6400-01 \mathrm{CO}_{2}$ mixer). Corresponding leaf water potentials $\left(\Psi_{l}\right)$ were calculated as above.

\subsection{Meteorological Data}

We measured soil moisture $(\theta ; \%)$ each day using time-domain reflectometry (LP TDR probes, Institute of Geophysics, Polish Academy of Sciences, Lublin, Poland) at four different depths (10, 30, 50, and $80 \mathrm{~cm}$ ), and recorded it every $30 \mathrm{~min}$ using the CR1000 datalogger (Campbell Scientific, North Logan, UT, USA). We recorded relative humidity $(\mathrm{RH}, \%)$ and air temperature $\left(\mathrm{Ta},{ }^{\circ} \mathrm{C}\right)$ every $60 \mathrm{~min}$ from June to September using a Zeno-3200-A-D Data Logger. We determined the vapor pressure deficit (VPD, $\mathrm{kPa}$ ) using measured Ta and $\mathrm{RH}$ using the following equation [26]:

$$
\mathrm{VPD}=\left(1-\frac{\mathrm{RH}}{100}\right) \times 0.6108 \times \operatorname{EXP}\left(\frac{17.27 \times \mathrm{Ta}}{T a+237.3}\right)
$$

\subsection{Data Treatment and Statistical Analysis}

Analysis of variance (ANOVA) was performed to test for differences in water relations between the species in growing seasons based on post hoc means using the least significant difference test (LSD). Regression analysis between stomatal conductance and vapor pressure deficit was performed. Regression analysis was also used with xylem water potentials in the dehydration treatment and leaf hydraulic characteristic. Pearson product-moment correlation was selected to test for the statistical 
significance of correlations between these parameters. A probability value of $p<0.05$ was used to indicate statistically significant differences. Data for vapor pressure deficit were analyzed using time series analysis. Data are presented as means with standard error; analysis was performed using SPSS 19.0 (IBM Corp., New York, United States). Figures were plotted using Origin 8.0 (OriginLab Corp., Massachusetts, USA).

\section{Results}

\subsection{Variability in Stomatal Conductance}

Diurnal variability in stomatal conductance $\left(g_{s}\right)$ in both-P. euphratica and T. ramosissima-increased at first in the morning and then decreased in the afternoon from June to September. From a general view for the two species, values of $g_{s}$ gradually decreased from June to September. As for the $g_{s}$ diurnal variability, the values increased in P. euphratica from 6:00 until 10:00 h, then decreased; $g_{s}$ values in P. euphratica did not differ at 10:00 and 14:00 h (Figure 2a). In T. ramosissima $g_{s}$ values increased from 6:00 until 14:00 h, then decreased; $g_{s}$ values in T. ramosissima at 10:00 and 14:00 $\mathrm{h}$ in June and July did not differ (Figure 2b).

Stomatal conductance $\left(g_{s}\right)$ was highly significantly correlated with vapor pressure deficit (VPD) in both species $(p<0.01)$, with correlation coefficients for P. euphratica and T. ramosissima at 0.317 and 0.338 , respectively (Figure 3a,b). Neither the leaf-specific hydraulic conductance of leaves $\left(k_{l l}\right)$ and $g_{s}$, nor $g_{s}$ and soil moisture were correlated in both species $(p>0.05)$. The mean soil moisture at $10-80 \mathrm{~cm}$ soil depth was lower in June and July than other two months, it increased significantly in August and then decreased from 25\% to 23\% in September (Figure 4). The reason was the discharge of water from the upper reaches of the Heihe River in early August.

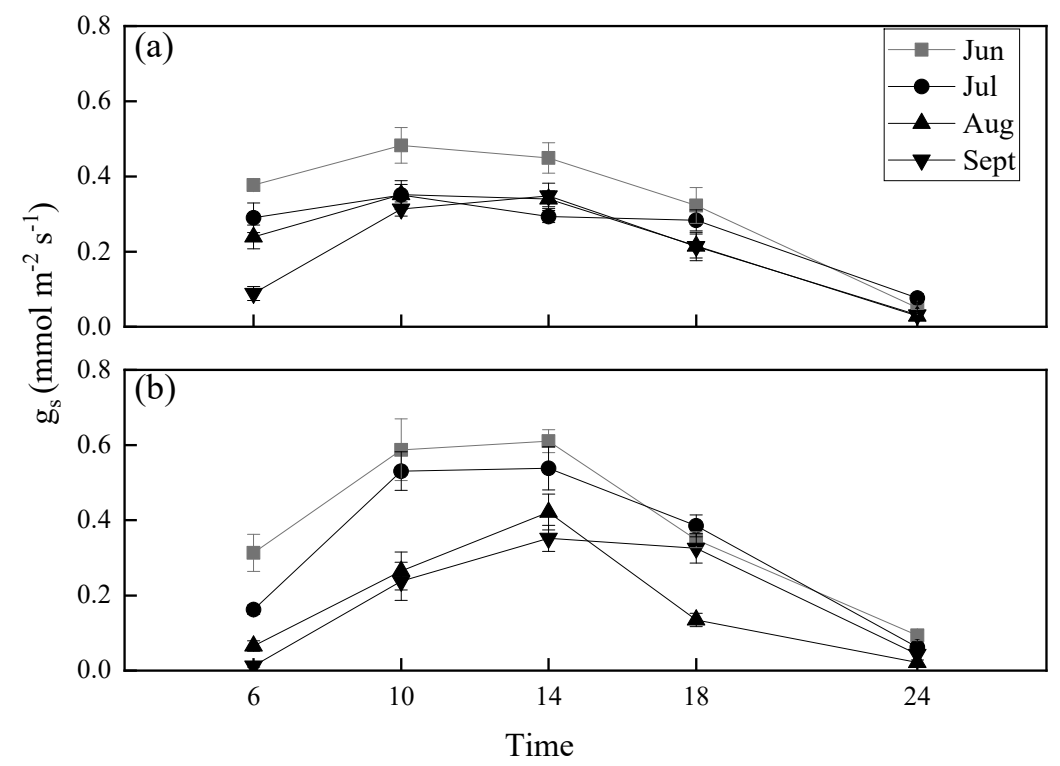

Figure 2. Diurnal variability in stomatal conductance $\left(g_{s}\right)$ during the growing season: (a) Populus euphratica leaves, (b) Tamarix ramosissima leaves. Data are means with standard error. 

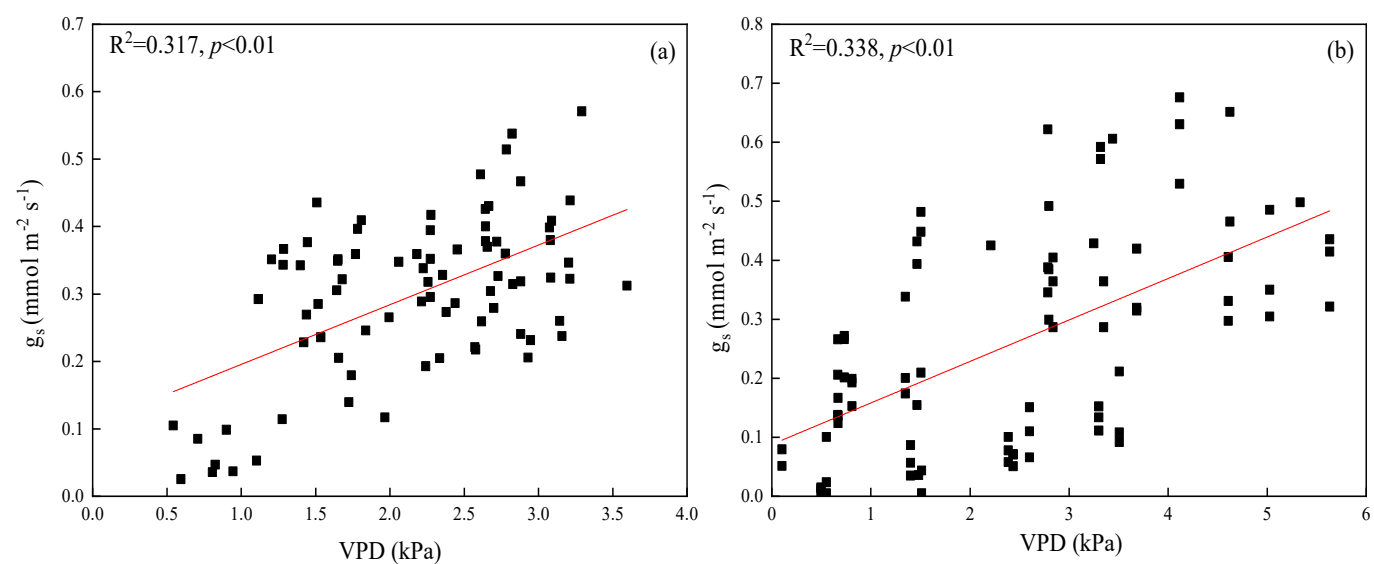

Figure 3. Regression relationships of stomatal conductance $\left(g_{s}\right)$ and vapor pressure deficit (VPD) for P. euphratica (a) and for T. ramosissima (b). All regressions shown were statistically highly significant $(p<0.01)$.

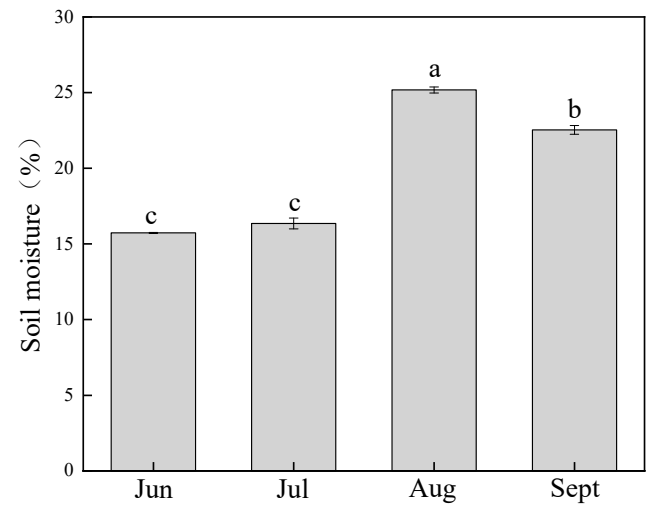

Figure 4. Monthly changes in soil moisture. Different letters denote significance levels based on ANOVA post hoc means using least significant difference (LSD) analysis $(p<0.05)$. Data are means with standard error.

\subsection{Variability in Water Potential and LSC}

Differences in LSC at different times of the day were not statistically significant $(p>0.05)$ - that is, the $L S C$ of the two species did not exhibit diurnal variability. Water potentials in P. euphratica branch $\left(\Psi_{x}\right)$ at noon were lower in July and August than in June and September. Leaf water potentials $\left(\Psi_{l}\right)$ did not differ significantly in these months (Figure 5a). $k_{l b}$ in P. euphratica were higher in July and August than in June and September. The LSC of the leaf did not differ significantly among these months (Figure $5 b$ ). The LSC of the leaf had the same trend as leaf water potential. The LSC of the branch had an opposite trend of the branch water potential, and it increased when branch water potential decreased. T. ramosissima branch water potential $\left(\Psi_{x}\right)$ did not differ significantly from the leaf water potential $\left(\Psi_{l}\right)$ from June to September (Figure 6a). The LSC of the leaf and branch were stable from June to September (Figure 6b). Additionally, $\Psi_{x}$ and $\Psi_{l}$ in T. ramosissima were lower than those in P. euphratica.

The LSC of the leaf in P. euphratica and T. ramosissima were negatively correlated with xylem water potential $\left(\Psi_{x}\right)$ after dehydration treatments $(p<0.05$, Figure $7 \mathrm{a}, \mathrm{b})$. Correlation coefficients for P. euphratica and T. ramosissima were 0.208 and 0.422 , respectively. Leaf water potential for both of the species decreased rapidly, with a decrease in branch water potential (Figure 8a,b). The LSC of the leaf increased when xylem water potential $\left(\Psi_{x}\right)$ decreased due to decreasing leaf water potentials $\left(\Psi_{l}\right)$ and declining $\Psi_{x}$, leading to hydraulic imbalance. 

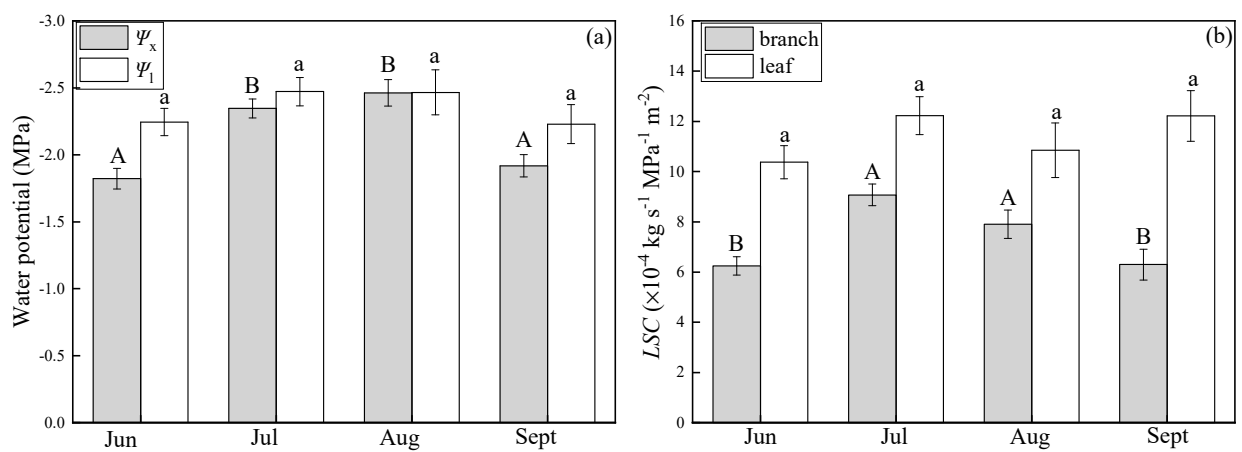

Figure 5. Changes in water potential (a) and leaf-specific hydraulic conductance (LSC) (b) in P. euphratica in growing seasons, (a): $\Psi_{x}$ (light-shaded boxes) indicates branch water potential. $\Psi_{l}$ (open boxes) indicates water potential of the leaf, (b): $k_{l b}$ (light-shaded boxes) indicates the LSC of the branch, $k_{l l}$ (open boxes) indicates the LSC of the leaf. Different letters denote significance levels based on ANOVA post hoc means using LSD analysis $(p<0.05)$. Data are means with standard error.
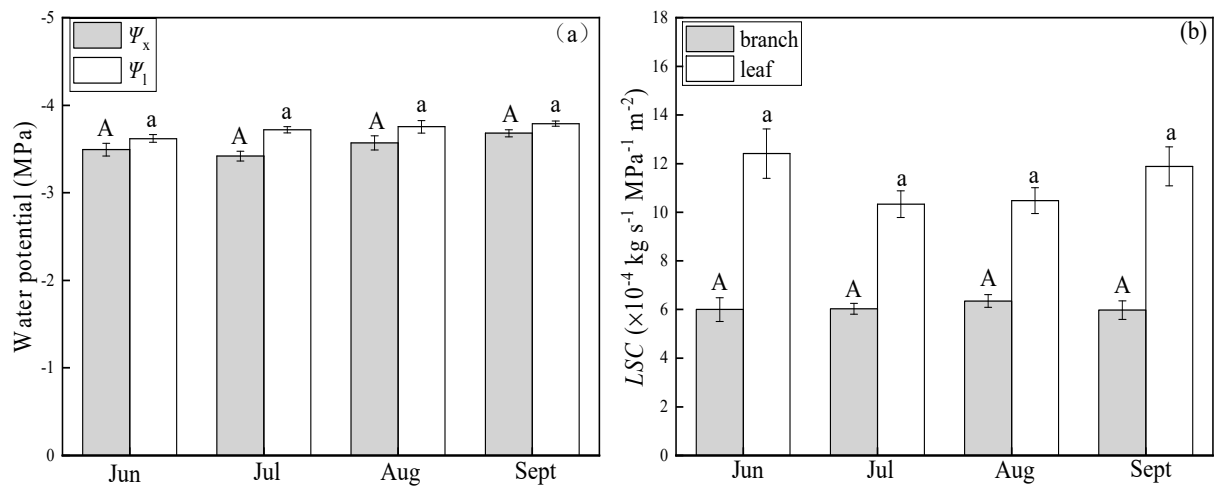

Figure 6. Changes in water potential (a) and leaf-specific hydraulic conductance (LSC) (b) in T. ramosissima in growing seasons, (a): $\Psi_{x}$ (light-shaded boxes) indicates branch water potential. $\Psi_{l}$ (open boxes) indicates water potential of leaves, (b): $k_{l b}$ (light-shaded boxes) indicates the LSC of the branch, $k_{l l}$ (open boxes) indicates the LSC of the leaf. Different letters denote significance levels based on ANOVA post hoc means using LSD analysis $(p<0.05)$. Data means with standard error.
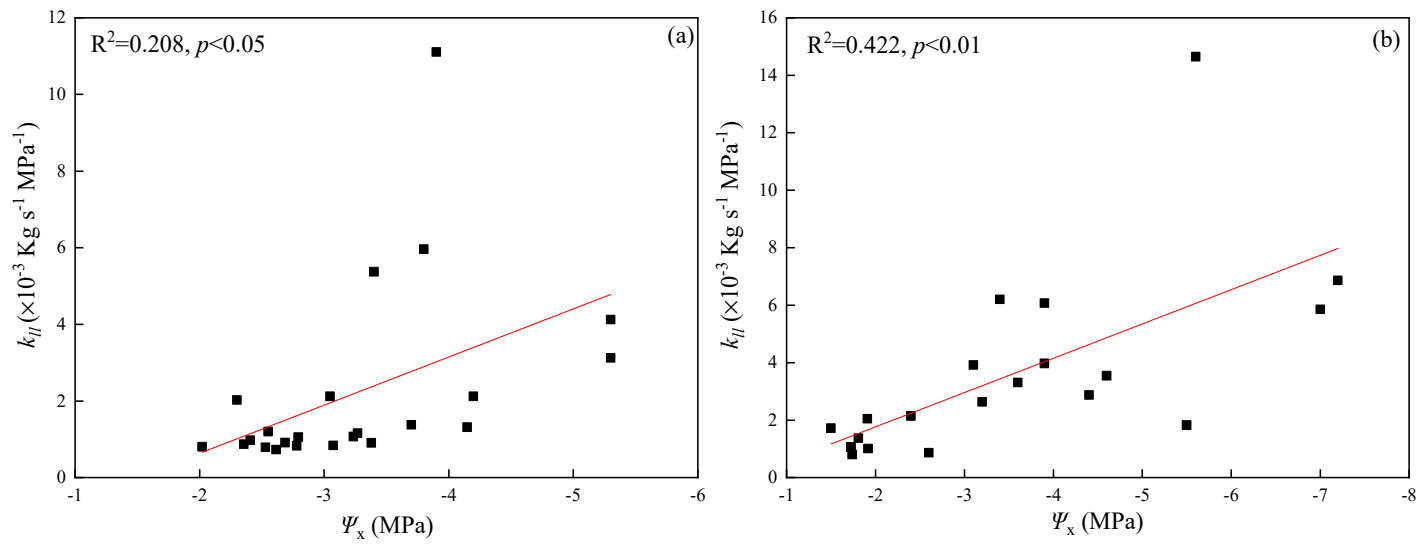

Figure 7. Regression analysis for dehydration treatments: (a) branch water potential $\left(\Psi_{x}\right)$ and the LSC of leaf blades $\left(k_{l l}\right)$ in P. euphratica, (b) branch water potential $\left(\Psi_{x}\right)$ and the LSC of leaf blades $\left(k_{l l}\right)$ in T. ramosissima. All regressions shown were statistically significant $(p<0.05)$. 

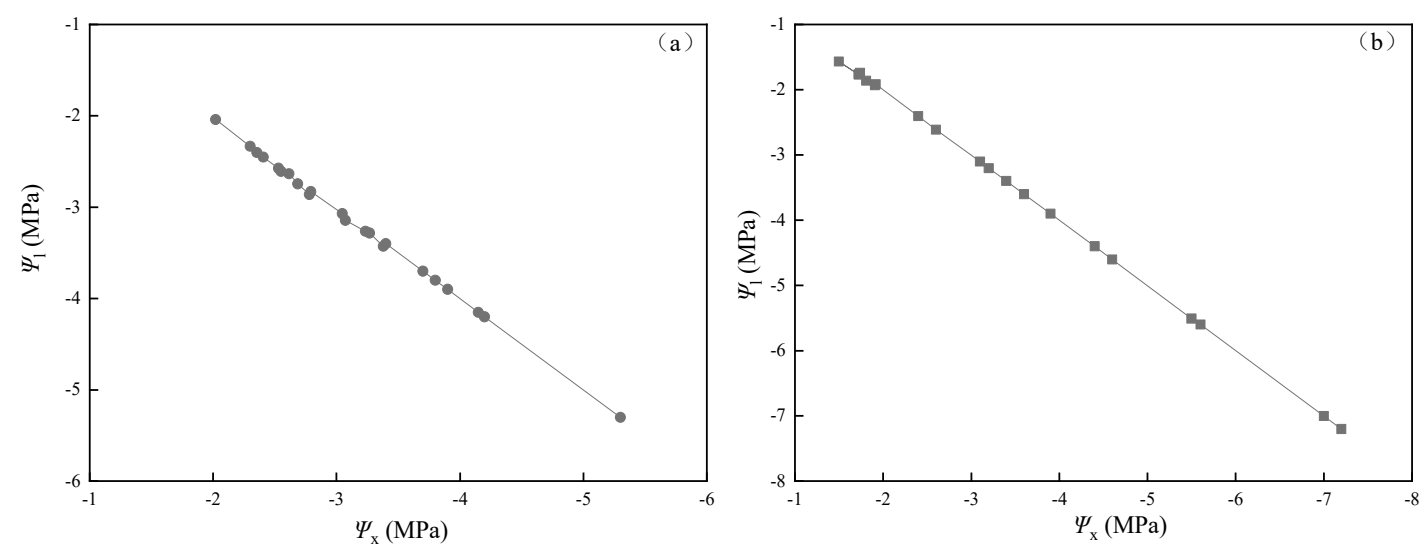

Figure 8. Dependence of leaf on xylem water potential in dehydration treatments for P. euphratica (a) and for T. ramosissima (b).

\subsection{Variability in Electrical Conductivity of Xylem Sap}

The electrical conductivity of xylem sap in T. ramosissima was slightly enhanced from June to July, then decreased from August to September. In P. euphratica, the electrical conductivity of xylem sap did not differ from June to August, and it decreased in September. The values for T. ramosissima were at least 4.5 times higher than those for P. euphratica (Figure 9).

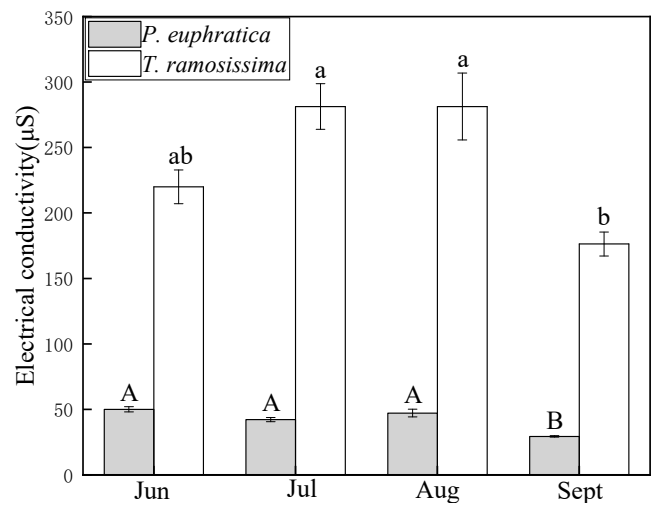

Figure 9. The electrical conductivity of xylem sap during the growing season. Light-shaded boxes indicate P. euphratica, and open boxes indicate T. ramosissima. Different letters denote significance levels based on ANOVA post hoc means using LSD analysis $(p<0.05)$. Data are means with standard error.

\section{Discussion}

\subsection{Regulation of Stomatal Conductance}

Vapor pressure deficit (VPD) was the driving force of stomatal regulation, and both P. euphratica and T. ramosissima exhibited monthly changes in the sensitivity of stomatal conductance to VPD. There was a close correlation between stomatal conductance and parameters of VPD. Leaf water potential remained constant throughout the growing season, due to the adjustment of stomatal conductance responding to VPD [27]. Strict regulation of stomatal conductance by water supply was necessary due to the high transpiration demand that is caused by high VPD during the growing season. The comprehensive analysis revealed a decrease in $g_{s}$. Meanwhile, the corresponding changes in stomatal conductance would reduce the risk of xylem cavitation during periods of high transpiration demand [28]. Previous studies showed that $g_{s}$ decreased when the environment for plant growth changed from wet to dry, or when $g_{s}$ increased when plants became rehydrated after the drought $[29,30]$. This is probably because previous research was based on the same environment except for dramatic changes in soil water conditions. In our study, soil moisture was mainly affected by the artificial discharge of water 
from the upper reaches of the Heihe River and had little direct relationship with $g_{s}$ during the growing season. This was probably because soil moisture during the growing season was above the lowest requirement for plant development. Meanwhile, under a different environment during the growing season, the effect of soil moisture on $g_{s}$ is complex. For stomatal conductance, the lower VPD revealed a weaker ability to perceive the water potential, which was a result of the multifactor functioning of soil moisture and other soil properties (e.g., temperature, salinity). When there is a certain change in soil moisture under a lower VPD, stomatal conductance might be less affected. In general, significant changes in soil moisture for plant development under the same environment would affect $g_{s}$ for the hydraulic integrity of plants in the soil-plant-air continuum.

Previous studies showed that hydraulic conductance acted as an important transpiration regulation factor, possibly through the amplification of the hydraulic signal for stomatal closure [31,32]. Some authors have shown that $g_{s}$ was related to leaf hydraulic characteristics; this was probably because leaf hydraulic characteristics of some species exhibited diurnal variability and were closely coupled to gas exchange, acting as a limitation to water loss to the atmosphere [32,33]. The leaf-specific hydraulic conductance (LSC) of the two species in this study did not exhibit diurnal variability; the light dependence of hydraulic conductance is probably not a general phenomenon, although it was essential in some species [34]. Diurnal values of $g_{s}$ and hydraulic characteristics were not related in either species, indicating that stomatal opening did not influence hydraulic conductance; this suggests that a very tight stomatal closure could have a possible impact on hydraulic characteristics [35]. Moreover, high resistance to water flow within the leaf accompanied by leaf water storage capacity may limit the ability of stomata to sense changes in xylem hydraulic conductance [36]. Previous studies showed that there was little relationship between leaf hydraulic conductance and $g_{s}$ in some species. Juglans regia treated with abscisic acid failed to open stomata, and an almost $50 \%$ loss of hydraulic conductance in Polystichum munitum minimally influenced stomatal conductance [35,37].

\subsection{Regulation of LSC}

Branch water potential in $T$. ramosissima was approximately $-3.5 \mathrm{MPa}$; these values were in the range of desert shrubs exhibiting stem water potentials between -3 and $-6 \mathrm{MPa}$, but much lower than those in P. euphratica [38]. Low water potential, which was significantly correlated with stomatal regulation, together with the LSC of the leaf may help T. ramosissima to maintain water uptake and growth under high transpirational demand, and it also affords T. ramosissima the capability to overcome hydraulic constraints imposed by long xylem pathways [39]. In our study, both the LSC of the leaf and water potentials of both species remained stable throughout the growing season and allowed normal transpiration. The dependence of leaf hydraulic characteristics on leaf water potential may be due to the fine-scale feedback loop between leaf water potential and cell turgor, which maintains leaf water potential at a steady-state at constant hydraulic conductance even under high evaporative demand [18]. This relationship illustrates an important link between the water status and water transport efficiency of leaves.

Variability in the LSC of the branch was similar to that of branch water potential. There was no significant difference in the leaf-specific hydraulic conductance of leafy branches in T. ramosissima with steady branch water potential during the growing season. The low water potential of the leaf may help T. ramosissima to maintain the stable water potential of the branch during the growing season. On the contrary, there were changes in the leaf-specific hydraulic conductance of leafy branches in P. euphratica with unstable branch potential. This relationship illustrates an essential link between water status and water transport efficiency both in the branches and the leaves. Changes in the hydraulic conductance of leafy branches caused by changes in water demand in conditions of low xylem water potential will be accompanied by the rapid regulation of transpiration, striving to maintain leaf water potentials to ensure the integrity of water transport and avoid xylem embolism $[40,41]$. The dehydration treatments resulted in an increase in the LSC of the leaf in both species due to a decrease in leaf water potential accompanied by the descending branch water potential. This revealed that the hydraulic system was 
controlled by a critical threshold in xylem water potential, which may induce the turgor loss of xylem embolism in an environment with widely fluctuating water status in the leaves [42]. Desert plants cannot maintain relatively constant LSC in the leaf, which maintained a stable water supply per leaf area when branch water potential fell below a critical threshold.

\subsection{Regulation of Ion Sensitivity}

The values of electrical conductivity in xylem sap reflected the ion concentration. Tolerance to low leaf water potentials in T. ramosissima may be explained by generally higher concentrations of osmotically active substances than were present in P. euphratica. Variability in ion concentration in xylem sap suggested that it changed in response to environmental changes. It has been demonstrated that the hydraulic conductance of xylem increased with an increase and decreased with a decrease in xylem sap ion concentration [11]. Variability in hydraulic conductance was consistent with the properties of pectins in pit membranes located in the walls of vessels, which could swell and shrink to regulate conductance [43]. Previous studies showed that the higher the ion concentration in xylem sap, the more the shrinkage of pectins in pit membranes, and the higher the increase in porosity of the vessel walls [9]. Ion concentration in plants was higher during the peak season than in the later stage of plant growth [9]. Growing season drought usually occurred during the peak season caused by intense transpiration in this area. Previous studies have shown that a seasonal maximum in ion concentration occurred in the second half of the summer for poplar [44,45].

Changes in ion concentration in xylem sap were detected in both species, and branch hydraulic conductance also differed between species. The ion sensitivity of xylem hydraulic conductance was evaluated by the degree of change when xylem hydraulic conductance was affected by the increase of ion concentration. It has been found that the ion sensitivity of xylem hydraulic conductance differs between species in vascular plants [46], and the species-specific values of ion sensitivity were high when leaf water potential decreased [47]. In T. ramosissima, stable leaf water potential revealed a steady water environment. Though ion concentration was very high in T. ramosissima, the water supply was sufficient, and an increase in hydraulic conductance through high ion sensitivity was unnecessary [9]. As a result, branch hydraulic conductance in T. ramosissima was maintained in the conditions without water deficit. We suppose that the difference in the ion sensitivity of xylem hydraulic conductance in the two species may be caused by a difference in the stability of water supply. Water resources in a temperate climate gradually decreased from spring to a minimum in the second half of the summer [9].

P. euphratica experienced a noticeable reduction in water supply in July and August. As water deficit in xylem progressed, xylem hydraulic conductance was enhanced by an increase in ion concentration in xylem sap in order to grow generally during a growing-season drought. A similar conclusion was also reached in studies of evergreens $[10,48]$. Both a lower water potential and the ion sensitivity of xylem hydraulic conductance induced an increase in hydraulic conductance. As a result, the branch hydraulic conductance of P. euphratica increased in the conditions of relative water deficit. The dehydration treatments showed that the homeostasis of leaf water potential depended on hydraulic balance in plants. Once severe drought occurred during the growing season, xylem hydraulic conductance was adjusted to enhance it. Hydraulic imbalance would take place if the adjustment of xylem hydraulic conductance failed. We conclude that the ion sensitivity of xylem hydraulic conductance can be important for the adaption of trees and the improvement of xylem hydraulic conductance during extreme seasonal drought.

\section{Conclusions}

We studied the water relations of P. euphratica and T. ramosissima using the data analysis of branches in these riparian tree species. Our study revealed that the mechanisms of water relations differed between the investigated species. Both responded to VPD with an adjustment of stomatal conductance in order to achieve homeostasis in leaf water potentials in the growing season. Our results indicated that there was an important link between water status and water transport efficiency both in 
the branches and the leaves. The leaf-specific hydraulic conductance of the branch was determined by water status in the branch, and the leaf-specific hydraulic conductance of the leaf was determined by water status in the leaf under. Because of the homeostasis in leaf water potentials, hydraulic conductance in leaves remained stable in both species. T. ramosissima, with a high ion concentration, exhibited a much lower water potential than P. euphratica and could achieve homeostasis both in branch and leaf water potentials. Meanwhile, the ion sensitivity of xylem hydraulic conductance was enhanced in drought. Improvement in the ion sensitivity of xylem hydraulic conductance was unnecessary without drought stress. As a result, branch dieback, which might be induced by deficits in water supply, could rarely be seen in T. ramosissima owing to the homeostasis in branch and leaf water status. The ion sensitivity of xylem hydraulic conductance in P. euphratica induced an increase in hydraulic conductance under a relative deficit in the water supply. The capacity of P. euphratica to maintain hydraulic balance was relatively weaker than that of $T$. ramosissima. In drought adaptation, severe drought might lead to branch dieback in P. euphratica faster than in T. ramosissima. We suppose that the difference among species in the ion sensitivity of xylem hydraulic conductance may be caused by different values in the water potential and the stability of water supply under drought stress. Our study highlights the importance of the ion sensitivity of xylem hydraulic conductance for the improvement of hydraulic conductance and riparian tree adaption to severe drought. Further research on the comparison of P. euphratica and T. ramosissima should address water relations in severe drought to increase the understanding of the internal mechanisms of drought acclimation.

Author Contributions: D.L. and J.S. collected experimental data, analyzed, and wrote the manuscript. X.Z., Y.G., H.L., J.Q. and G.G. participated equally in conceptualization, data analysis, and manuscript preparation and review.

Funding: This research was funded by the National Key R\&D Program of China (No.2016YFC0400908, 2016YFC0501009), Major Science and Technology Project in Inner Mongolia Autonomous Region (zdzx2018057), Chinese Academy of Sciences Innovative Cross Team Project (JCTD-2019-19) and Fund Project of Shaanxi Key Laboratory of Land Consolidation (2018-JC13).

Acknowledgments: Thanks to Kathryn B. Piatek for her editorial suggestions on the spelling and grammar of manuscripts. The authors also record sincere appreciation for helpful and constructive comments made by reviewers of the draft manuscript.

Conflicts of Interest: The authors declare no conflicts of interest.

\section{References}

1. Engelbrecht, B.M.; Comita, L.S.; Condit, R.; Kursar, T.A.; Tyree, M.T.; Turner, B.L.; Hubbell, S.P. Drought sensitivity shapes species distribution patterns in tropical forests. Nature 2007, 447, 80. [CrossRef] [PubMed]

2. Hetherington, A.M.; Woodward, F.I. The role of stomata in sensing and driving environmental change. Nature 2003, 424, 901. [CrossRef] [PubMed]

3. Cernusak, L.A.; Marshall, J.D. Responses of foliar $\delta 13 C$, gas exchange and leaf morphology to reduced hydraulic conductivity in Pinus monticola branches. Tree Physiol. 2001, 21, 1215-1222. [CrossRef] [PubMed]

4. Raven, J.A. Selection pressures on stomatal evolution. New Phytol. 2010, 153, 371-386. [CrossRef]

5. Cochard, H.; Herbette, S.; Hernández, E.; Hölttä, T.; Mencuccini, M. The effects of sap ionic composition on xylem vulnerability to cavitation. J. Exp. Bot. 2009, 61, 275-285. [CrossRef] [PubMed]

6. Hochberg, U.; Bonel, A.G.; David-Schwartz, R.; Degu, A.; Fait, A.; Cochard, H.; Peterlunger, E.; Herrera, J.C. Grapevine acclimation to water deficit: The adjustment of stomatal and hydraulic conductance differs from petiole embolism vulnerability. Planta 2017, 245, 1091-1104. [CrossRef]

7. Sack, L.; Tyree, M.T.; Holbrook, N.M. Leaf hydraulic architecture correlates with regeneration irradiance in tropical rainforest trees. New Phytol. 2005, 167, 403-413. [CrossRef]

8. Sack, L.; Holbrook, N.M. Leaf hydraulics. Annu. Rev. Plant Biol. 2006, 57, 361-381. [CrossRef]

9. Aasamaa, K.; Sõber, A. Sensitivity of stem and petiole hydraulic conductance of deciduous trees to xylem sap ion concentration. Biol. Plantarum. 2010, 54, 299-307. [CrossRef] 
10. Gascó, A.; Salleo, S.; Gortan, E.; Nardini, A. Seasonal changes in the ion-mediated increase of xylem hydraulic conductivity in stems of three evergreens: Any functional role? Phys. Plantarum. 2010, 129, 597-606. [CrossRef]

11. Leperen, W.V.; Meeteren, U.V.; Gelder, H.V. Fluid ionic composition influences hydraulic conductance of xylem conduits. J. Exp. Bot. 2000, 51, 769.

12. Zwieniecki, M.A.; Hutyra, L.; Thompson, M.V.; Holbrook, N.M. Dynamic changes in petiole specific conductivity in red maple (Acer rubrum L.), tulip tree (Liriodendron tulipifera L.) and northern fox grape (Vitis labrusca L.). Plant Cell Environ. 2000, 23, 407-414. [CrossRef]

13. Chen, Y.; Chen, Y.; Xu, C.; Li, W. Groundwater depth affects the daily course of gas exchange parameters of Populus euphratica in arid areas. Environ. Earth Sci. 2012, 66, 433-440. [CrossRef]

14. Si, J.; Feng, Q.; Cao, S.; Yu, T.; Zhao, C. Water use sources of desert riparian Populus euphratica forests. Environ. Monit. Assess. 2014, 186, 5469-5477. [CrossRef] [PubMed]

15. Pan, Y.; Chen, Y.; Chen, Y.; Wang, R.; Ren, Z. Impact of groundwater depth on leaf hydraulic properties and drought vulnerability of Populus euphraticain the Northwest of China. Trees 2016, 30, 2029-2039. [CrossRef]

16. Zhou, H.; Chen, Y.; Li, W.; Ayup, M. Xylem hydraulic conductivity and embolism in riparian plants and their responses to drought stress in desert of Northwest China. Ecohydrology 2013, 6, 984-993. [CrossRef]

17. Rzepecki, A.; Zeng, F.; Thomas, F. Xylem anatomy and hydraulic conductivity of three co-occurring desert phreatophytes. J. Arid Environ. 2011, 75, 338-345. [CrossRef]

18. Gries, D.; Zeng, F.; Foetzki, A.; Arndt, S.K.; Bruelheide, H.; Thomas, F.M.; Zhang, X.; Runge, M. Growth and water relations of Tamarix ramosissima and Populus euphratica on Taklamakan desert dunes in relation to depth to a permanent water table. Plant Cell Environ. 2003, 26, 725-736. [CrossRef]

19. Si, J.H.; Chang, Z.Q.; Su, Y.H.; Xi, H.Y.; Feng, Q. Stomatal conductance characteristics of Populus euphratica leaves and response to environmental factors in the extreme arid region. Acta Bot. Boreal.-Occident. Sin. 2008, $28,125$.

20. Tyree, M.T.; Patino, S.; Bennink, J.; Alexander, J. Dynamic measurements of roots hydraulic conductance using a high-pressure flowmeter in the laboratory and field. J. Exp. Bot. 1995, 46, 83-94. [CrossRef]

21. Sack, L.; Melcher, P.J.; Zwieniecki, M.A.; Holbrook, N.M. The hydraulic conductance of the angiosperm leaf lamina: A comparison of three measurement methods. J. Exp. Bot. 2002, 53, 2177-2184. [CrossRef] [PubMed]

22. Raimondo, F.; Trifilò, P.; Gullo, M.A.L.; Buffa, R.; Nardini, A.; Salleo, S. Effects of reduced irradiance on hydraulic architecture and water relations of two olive clones with different growth potentials. Environ. Exp. 2009, 66, 249-256. [CrossRef]

23. Alsina, M.M.; Smart, D.R.; Bauerle, T.; De Herralde, F.; Biel, C.; Stockert, C.; Negron, C.; Save, R. Seasonal changes of whole root system conductance by a drought-tolerant grape root system. J. Exp. Bot. 2011, 62, 99-109. [CrossRef] [PubMed]

24. Yangyang, L.I.; Chen, W.; Chen, J.; Shi, H. Vulnerability to drought-induced cavitation in shoots of two typical shrubs in the southern Mu Us Sandy Land, China. J. Arid Land 2016, 8, 125-137.

25. Nardini, A.; Gascò, A.; Trifilò, P.; Lo Gullo, M.A.; Salleo, S. Ion-mediated enhancement of xylem hydraulic conductivity is not always suppressed by the presence of $\mathrm{Ca}^{2+}$ in the sap. J. Exp. Bot. 2007, 58, 2609-2615. [CrossRef] [PubMed]

26. Campbell, G.S.; Norman, J.M. An Introduction to Environmental Biophysics; Springer: Berlin, Germany, 1998.

27. Oren, R.; Sperry, J.S.; Katul, G.G.; Pataki, D.E.; Ewers, B.E.; Phillips, N.; Schäfer, K.V.R. Survey and synthesis of intra- and interspecific variation in stomatal sensitivity to vapour pressure deficit. Plant Cell Environ. 2010, 22, 1515-1526. [CrossRef]

28. Mcdowell, N.; Pockman, W.T.; Allen, C.D.; Breshears, D.D.; Cobb, N.; Kolb, T.; Plaut, J.; Sperry, J.; West, A.; Williams, D.G. Mechanisms of plant survival and mortality during drought: Why do some plants survive while others succumb to drought? New Phytol. 2010, 178, 719-739. [CrossRef] [PubMed]

29. Chen, Y.P.; Chen, Y.N.; Xu, C.C. Photosynthesis and water use efficiency of Populus euphratica in response to changing groundwater depth and CO2 concentration. Environ. Earth Sci. 2011, 62, 119-125. [CrossRef]

30. Wang, N.; Gao, J.; Zhang, S. Overcompensation or limitation to photosynthesis and root hydraulic conductance altered by rehydration in seedlings of sorghum and maize. Crop J. 2017, 5, 337-344. [CrossRef]

31. Brodribb, T.J.; Holbrook, N.M. Stomatal closure during leaf dehydration, correlation with other leaf physiological traits. Plant Physiol. 2003, 132, 2166-2173. [CrossRef] 
32. Brodribb, T.; Holbrook, N.M. Diurnal depression of leaf hydraulic conductance in a tropical tree species. Plant Cell Environ. 2004, 27, 820-827. [CrossRef]

33. Zhang, Y.; Meinzer, F.; Qi, J.; Goldstein, G.; Cao, K. Midday stomatal conductance is more related to stem rather than leaf water status in subtropical deciduous and evergreen broadleaf trees. Plant Cell Environ. 2013, 36, 149-158. [CrossRef] [PubMed]

34. Li, D.; Si, J.; Zhang, X.; Gao, Y.; Wang, C.; Luo, H.; Qin, J.; Gao, G. Hydraulic Characteristics of Populus euphratica in an Arid Environment. Forests 2019, 10, 407. [CrossRef]

35. Tyree, M.T.; Nardini, A.; Salleo, S.; Sack, L.; El Omari, B. The dependence of leaf hydraulic conductance on irradiance during HPFM measurements: Any role for stomatal response? J. Exp. Bot. 2004, 56, 737-744. [CrossRef] [PubMed]

36. Zwieniecki, M.A.; Holbrook, N.M. Diurnal variation in xylem hydraulic conductivity in white ash (Fraxinus americana L.), red maple (Acer rubrum L.) and red spruce (Picea rubens Sarg.). Plant Cell Environ. 1998, 21, 1173-1180.

37. Brodersen, C.R.; Rico, C.; Guenni, O.; Pittermann, J. Embolism spread in the primary xylem of Polystichum munitum: Implications for water transport during seasonal drought. Plant Cell Environ. 2016, 39, 338-346. [CrossRef]

38. Sperry, J.S.; Hacke, U.G. Desert Shrub Water Relations with Respect to Soil Characteristics and Plant Functional Type. Funct. Ecol. 2002, 16, 367-378. [CrossRef]

39. Bruelheide, H.; Jandt, U. Vegetation types in the foreland of the Qira Oasis: Present distribution and changes during the last decades. In Ecophysiology and Habitat Requirements of Perennial Species in the Taklimakan Desert; Shaker Verlag GmbH: Aachen, Germany, 2004; pp. 27-34.

40. Zhu, S.D.; Cao, K.F. Hydraulic properties and photosynthetic rates in co-occurring lianas and trees in a seasonal tropical rainforest in southwestern China. Plant Ecol. 2009, 204, 295-304. [CrossRef]

41. Pivovaroff, A.L.; Pasquini, S.C.; De Guzman, M.E.; Alstad, K.P.; Stemke, J.S.; Santiago, L.S. Multiple strategies for drought survival among woody plant species. Funct. Ecol. 2016, 30, 517-526. [CrossRef]

42. Franks, P.J.; Drake, P.L.; Froend, R.H. Anisohydric but isohydrodynamic: Seasonally constant plant water potential gradient explained by a stomatal control mechanism incorporating variable plant hydraulic conductance. Plant Cell Environ. 2007, 30, 19-30. [CrossRef]

43. Lopez-portilloI, J.; Ewers, F.W.; Angeles, G. Sap salinity effects on xylem conductivity in two mangrove species. Plant Cell Environ. 2005, 28, 1285-1292. [CrossRef]

44. Bahrun, A.; Jensen, C.R.; Asch, F.; Mogensen, V.O. Drought-induced changes in xylem pH, ionic composition, and ABA concentration act as early signals in field-grown maize (Zea mays L.). J. Exp. Bot. 2002, 53, 251-263. [CrossRef] [PubMed]

45. Siebrecht, S.; Herdel, K.; Schurr, U.; Tischner, R. Nutrient translocation in the xylem of poplar-diurnal variations and spatial distribution along the shoot axis. Planta 2003, 217, 783-793. [CrossRef] [PubMed]

46. Boyce, C.K.; Zwieniecki, M.A.; Cody, G.D.; Jacobsen, C.; Wirick, S.; Knoll, A.H.; Holbrook, N.M. Evolution of xylem lignification and hydrogel transport regulation. Proc. Natl. Acad. Sci. USA 2004, 101, 17555-17558. [CrossRef]

47. Aasamaa, K.; Niinemets, Ü.; Sõber, A. Leaf hydraulic conductance in relation to anatomical and functional traits during Populus tremula leaf ontogeny. Tree Phys. 2005, 25, 1409-1418. [CrossRef]

48. Trifilò, P.; Lo Gullo, M.A.; Salleo, S.; Callea, K.; Nardini, A. Xylem embolism alleviated by ion-mediated increase in hydraulic conductivity of functional xylem: Insights from field measurements. Tree Phys. 2008, 28, 1505-1512. [CrossRef] [PubMed]

(C) 2019 by the authors. Licensee MDPI, Basel, Switzerland. This article is an open access article distributed under the terms and conditions of the Creative Commons Attribution (CC BY) license (http://creativecommons.org/licenses/by/4.0/). 